Journal of Electronics and Informatics (2019)

Vol.01/ No. 02

Pages: $89-98$

http://www.irojournals.com/iroei/

DOI: https://doi.org/10.36548/jei.2019.2.004

\title{
NEURAL NETWORK ANALYSIS FOR TUMOR INVESTIGATION AND CANCER PREDICTION
}

\author{
Dr. T. Vijayakumar, \\ Professor, \\ Department of ECE, \\ GNIT, Hyderabad, \\ India. Email: vishal_16278@yahoo.co.in
}

\begin{abstract}
Predicting the category of tumors and the types of the cancer in its early stage remains as a very essential process to identify depth of the disease and treatment available for it. The neural network that functions similar to the human nervous system is widely utilized in the tumor investigation and the cancer prediction. The paper presents the analysis of the performance of the neural networks such as the, FNN (Feed Forward Neural Networks), RNN (Recurrent Neural Networks) and the CNN (Convolutional Neural Network) investigating the tumors and predicting the cancer. The results obtained by evaluating the neural networks on the breast cancer Wisconsin original data set shows that the CNN provides $43 \%$ better prediction than the FNN and $25 \%$ better prediction than the RNN.
\end{abstract}

Keywords: Cancer Diagnosis, Cancer Prediction, Tumor Investigation, Neural Networks, Improved Performance

\section{INTRODUCTION}

Though the world strives to more and more advancements with the rapid modernization and the developing technologies, there are few things that are still tedious and challenging; on such thing is the cancer identification. The modernization has also brought in changes in the dress people wear, the way people live including the food we take. The change followed in the life style has the increased the vulnerability to disease like cancer, kidney defects etc.

Every year more than 40,000 people are diagnosed with cancer that affects the parts like bladder, colon and recta, endometrial, kidney, leukemia, liver, melanoma, non-Hodgkin's lymphoma, pancreatic, thyroid, breast etc. The physicians usually identify the cancer by its location in the human body and the tissue that it forms in. In most cases

ISSN: 2582-3825 (online) 
Journal of Electronics and Informatics (2019)

Vol.01/ No. 02

Pages: $89-98$

http://www.irojournals.com/iroei/

DOI: https://doi.org/10.36548/jei.2019.2.004

the doctors identify the cancer in patients only in its advanced stage as some tumors that are developed by cancer does not exhibit symptoms until their advanced stage or exhibit symptoms that are unrelated to cancer.

The possibility of early detection remains very low as the technologies used are still not able to diagnose the cancer with symptoms presented in the early stage, only very few cases were identified to have cancer in the initial stage and were recovered. The death due to the cancer keeps on increasing exponentially every year

Many researches were done to improve the cancer diagnosis to investigate the tumor and the identifying the type of cancer, the paper present the performance analysis of the neural networks in investigating the tumors and detecting the cancer.

The remaining paper is arranged with the back ground providing the capability of the neural networks, in section 2, the investigation and the prediction model for the cancer diagnoses using the neural networks in section 3 performance analyses in section 4 and the conclusion in section 5

\section{BACKGROUND}

The neural network are viewed as the powerful machine learning methods that are broadly used in learning the data illustrations at a various levels of perception, and very useful in variety of applications such as the clustering classification, prediction, reconstruction and recognition etc.

The basic functionality of the neural networks in predicting a disease can be categorized as the preprocessing and the filtering methods, predicting that is the classification and clustering. The fig. 1 below provides the methods and the functioning of the neural networks.

ISSN: 2582-3825 (online) 
Journal of Electronics and Informatics (2019)

Vol.01/ No. 02

Pages: 89- 98

http://www.irojournals.com/iroei/

DOI: https://doi.org/10.36548/jei.2019.2.004

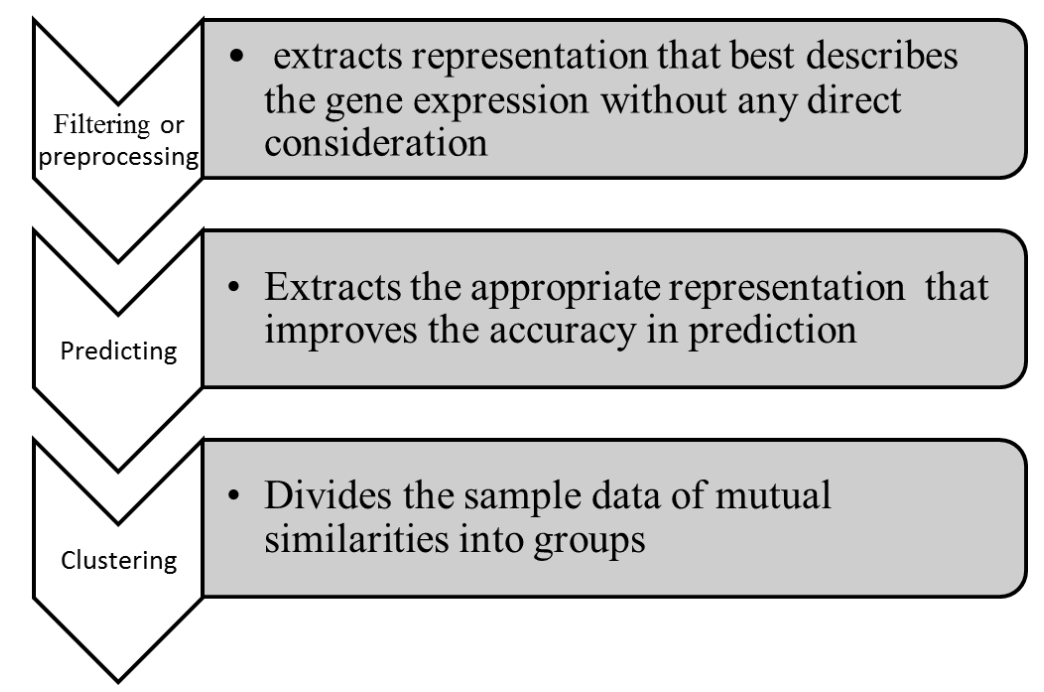

Fig.1 Methods and Functioning of Neural Networks

The Neural networks are capable enough to solve the problems that are non-linear as well as complex and identify the universal input put mappings, the input fed into the network is termed as the training data to prepare the network, for predicting the results. The following section presets the different types of the neural network model used to investigate and predict the cancer.

\section{NEURAL NETWORK BASED CANCER PREDICTION MODEL}

Feed forward neural network: It is simplest form of neural network, in which the input is conveyed in one direction. The data moves into the input nodes and moves out from the output nodes, it does not have any hidden layers, as it holds just the front propagated wave and has no back propagation. It basically uses the classifying activation function. The figure .2 below shows the single layer FNN 
Journal of Electronics and Informatics (2019)

Vol.01/ No. 02

Pages: $89-98$

http://www.irojournals.com/iroei/

DOI: https://doi.org/10.36548/jei.2019.2.004

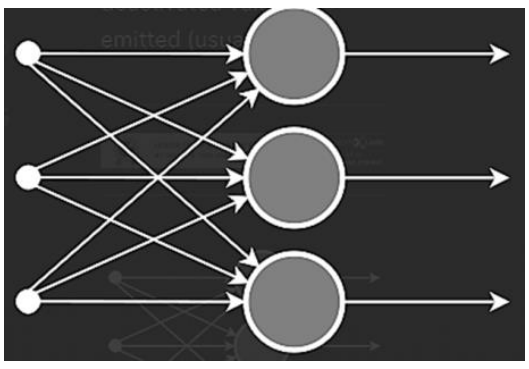

Fig.2 Single Layer FNN

The sum of products of inputs holding the weight and the data are estimated and given to the output, the output of the network is taken into consideration if it is above the verge level set usually zero and rejects if below Zero.

Recurrent Neural Network: RNN preserves the output of the layer by feeding the output back to the input to predict the layer results; the first layer in the network is formed similar to the FNN performing the product of sum of the weights and the data. That is at each step the network ensures that every neuron has the trace of the previous time-step. The RNN starts with the front propagation initially and observes the information required for future use. If the prediction is wrong, then estimates the error rate to alter the network to provide correct prediction in the back propagation. The flow chart below in fig. 3 shows the steps involved in the neural network.

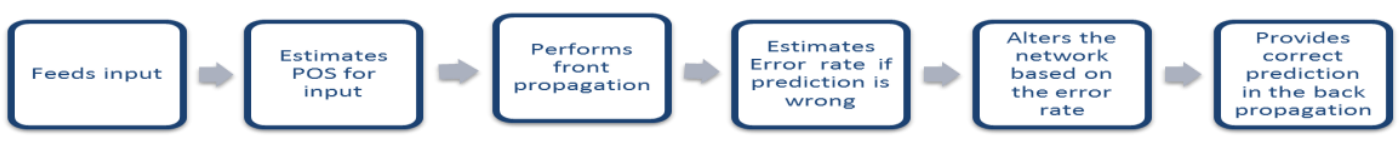

Fig.3 Recurrent Neural Network

ISSN: 2582-3825 (online) 
Journal of Electronics and Informatics (2019)

Vol.01/ No. 02

Pages: $89-98$

http://www.irojournals.com/iroei/

DOI: https://doi.org/10.36548/jei.2019.2.004

The fig. 4 below provides the schematic of the RNN architecture illustrated by Raj, Jennifer S., and J. Vijitha Ananthi. Comprised of one hidden layer with the time delay set to $\mathrm{Z}^{-1}$,

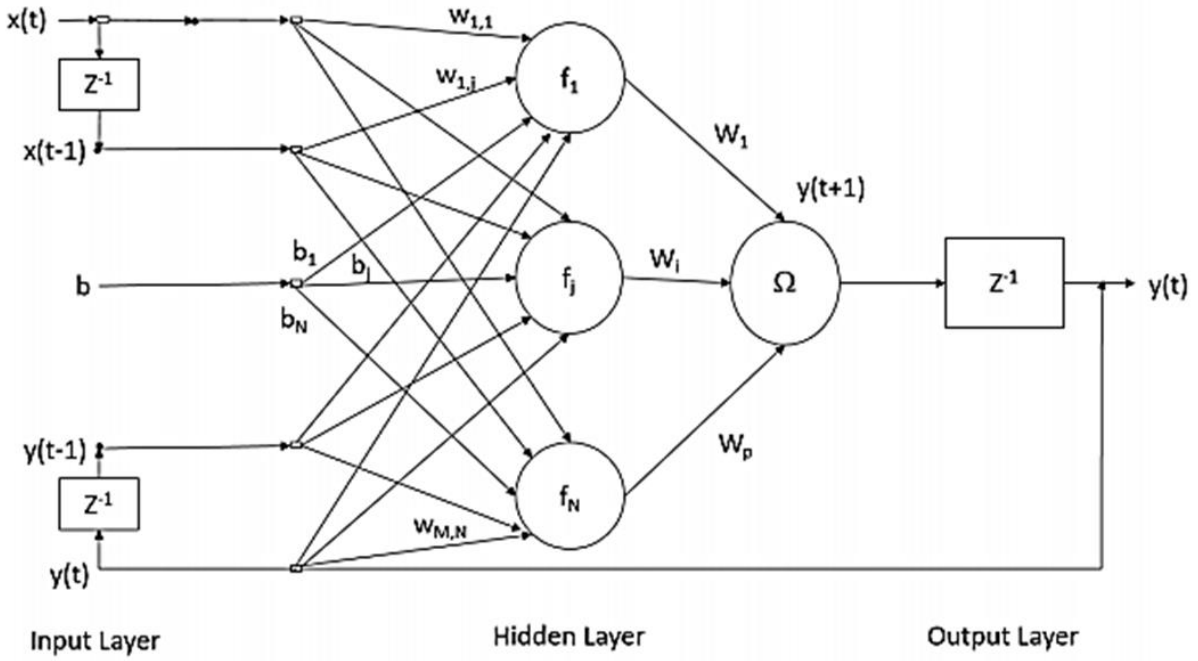

Fig.4 Schematic of RNN by Raj, Jennifer S., and J. Vijitha Ananthi.

Convolutional Neural Network: The convolutional neural network termed as CNN is very much similar to the FNN, but the neuron learns the weight and the biases. They possess a different architecture when compared to the neural network. It is comprised of two primary stages feature extraction and classification where in feature extraction the network does a continues convolution and pooling operations in order to detect the features in the image and utilizes the fully connected layer to classify the extracted features, the layer $\mathrm{s}$ in the CNN are arranged in three dimensions separating the neurons from one layer to next. The output is usually reduced to single vectors based on the probability scores. The figure. 5 below shows the architecture of the CNN

ISSN: 2582-3825 (online) 
Journal of Electronics and Informatics (2019)

Vol.01/ No. 02

Pages: $89-98$

http://www.irojournals.com/iroei/

DOI: https://doi.org/10.36548/jei.2019.2.004

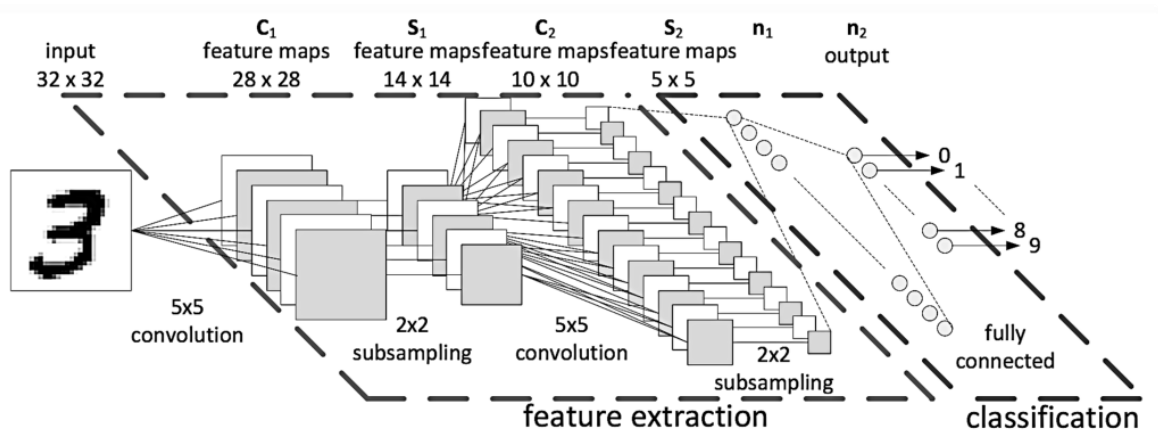

Fig.5 CNN Architecture [12]

The CNN does the convolution employing the filter or a kernel by scanning the image from the top to the bottom, the process is continued transforming the width of the screen until the entire image is scanned. The filter or the kernel multiplies its own values with the overlapping values and adds them to the output single value for each overlap until the whole message is passed through. Similar computation is done to estimate the other output value, every value computed remains sensitive only to the particular region in the image. The convolution in the initial layer remains responsible for handling low-level features such as the edges, orientation, gradient, color etc.

\section{PERFORMANCE ANALYSIS}

The above three methods are evaluated using the breast cancer Wisconsin original data set, to evinces its investigation and the prediction capability, every model were trained with 7564 images and was tested using the 3456 images obtained from the original dataset of the breast cancer Wisconsin. The results obtained tested for the Accuracy in training and prediction along with the F1 score, recall, true positive and the false positive. The figure .6 below shows the accuracy in prediction by the three methods for different number of Epochs.

ISSN: 2582-3825 (online) 
Journal of Electronics and Informatics (2019)

Vol.01/ No. 02

Pages: 89- 98

http://www.irojournals.com/iroei/

DOI: https://doi.org/10.36548/jei.2019.2.004

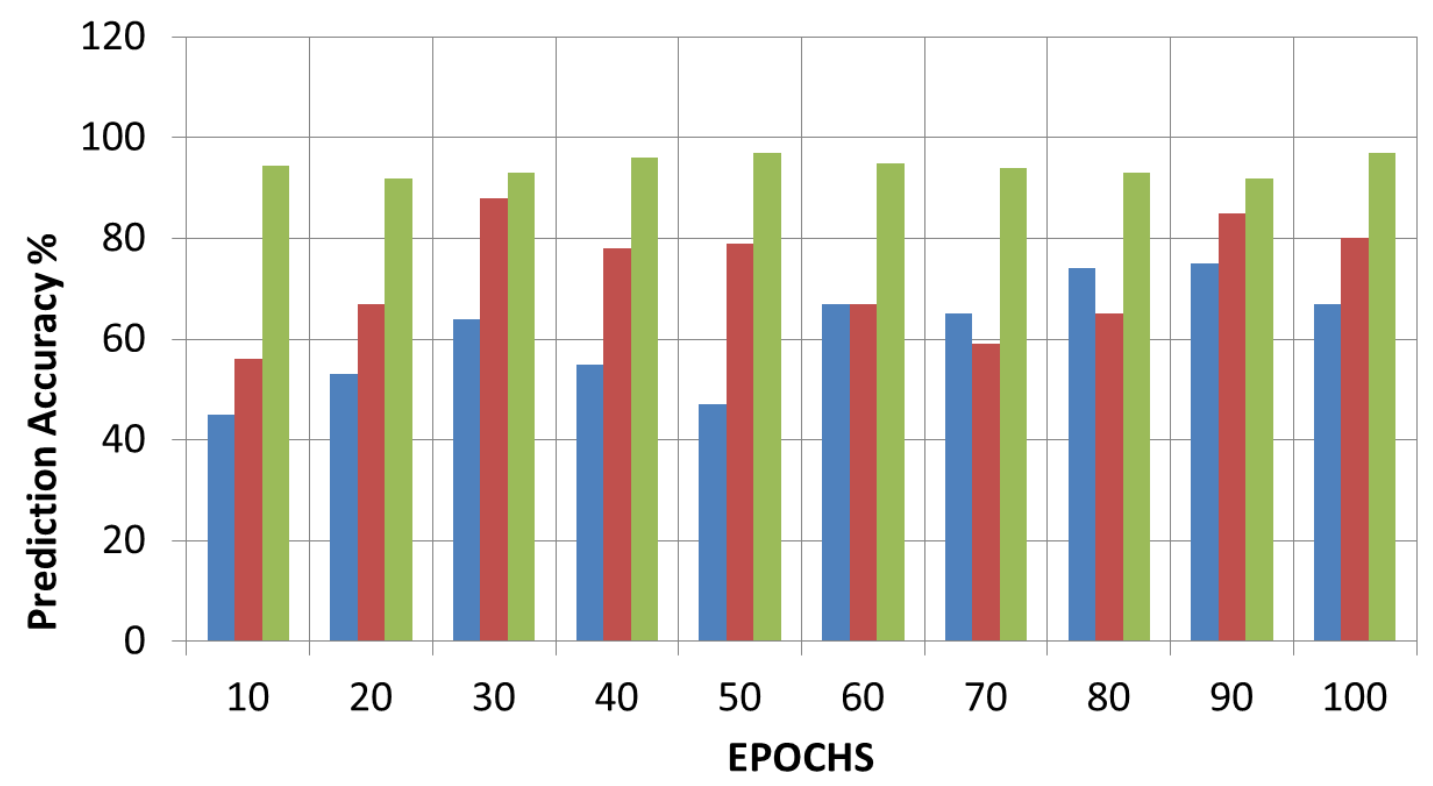

FNN $\square$ RNN $\square$ CNN

Fig.6 Accuracy Percentage

The table below provides the recall, F1 score and the true positive and the false negative for the FNN, RNN and CNN 
Journal of Electronics and Informatics (2019)

Vol.01/ No. 02

Pages: $89-98$

http://www.irojournals.com/iroei/

DOI: https://doi.org/10.36548/jei.2019.2.004

\begin{tabular}{|c|c|l|l|l|l|}
\hline $\begin{array}{c}\text { Neural } \\
\text { Networks }\end{array}$ & Precision & F1 Score & Recall & $\begin{array}{l}\text { True } \\
\text { positive }\end{array}$ & $\begin{array}{l}\text { False } \\
\text { Positive }\end{array}$ \\
\hline FNN & $60 \%$ & .7654 & .4567 & .775 & .7856 \\
\hline RNN & $75 \%$ & .7890 & .5546 & .734 & .5674 \\
\hline CNN & $95 \%$ & .9923 & .9856 & .997 & .2345 \\
\hline
\end{tabular}

Table.1 Comparison Table

The results obtained from the fig. 6 and the table .1 shows that the CNN shows better prediction accuracy than the FNN and RNN.

\section{CONCLUSION}

The paper presents the analysis of the neural network to have an early stage prediction for the cancer disease. it considers the RNN,FNN and the CNN to identify a better model to predict the cancer disease, all the three models where subjected to the original data set of breast cancer Wisconsin, the tested results showed that the CNN with the maximum pooling operation showed a better performance in prediction compared to the other two methods. in future the paper is proceed with employing the capsule networks in investigating and predicting the tumors and the cancer respectively.

ISSN: 2582-3825 (online) 
Journal of Electronics and Informatics (2019)

Vol.01/ No. 02

Pages: 89- 98

http://www.irojournals.com/iroei/

DOI: https://doi.org/10.36548/jei.2019.2.004

\section{References}

[1] Chandy, Abraham. "A REVIEW ON IOT BASED MEDICAL IMAGING TECHNOLOGY FOR HEALTHCARE APPLICATIONS." Journal of Innovative Image Processing (JIIP) 1, no. 01 (2019): $51-60$

[2] Manoharan, Samuel, and Narain Ponraj. "PRECISION IMPROVEMENT AND DELAY REDUCTION IN SURGICAL TELEROBOTICS." Journal of Artificial Intelligence 1, no. 01 (2019): 28-36.

[3] Koresh, Mr H. James Deva. "COMPUTER VISION BASED TRAFFIC SIGN SENSING FOR SMART TRANSPORT." Journal of Innovative Image Processing (JIIP) 1, no. 01 (2019): 11-19. Bashar, Abul. "SURVEY ON EVOLVING DEEP LEARNING NEURAL NETWORK ARCHITECTURES." Journal of Artificial Intelligence 1, no. 02 (2019): 73-82.

[4] Sathesh, A. "PERFORMANCE ANALYSIS OF GRANULAR COMPUTING MODEL IN SOFT COMPUTING PARADIGM FOR MONITORING OF FETAL ECHOCARDIOGRAPHY." Journal of Soft Computing Paradigm (JSCP) 1, no. 01 (2019): 14-23.

[5] Raj, Jennifer S., and J. Vijitha Ananthi. "RECURRENT NEURAL NETWORKS AND NONLINEAR PREDICTION IN SUPPORT VECTOR MACHINES." Journal of Soft Computing Paradigm (JSCP) 1, no. 01 (2019): 33-40.

[6] Duraipandian, M. "PERFORMANCE EVALUATION OF ROUTING ALGORITHM FOR MANET BASED ON THE MACHINE LEARNING TECHNIQUES." Journal of trends in Computer Science and Smart technology (TCSST) 1, no. 01 (2019): 25-38.

[7] Smys, S. "DDOS ATTACK DETECTION IN TELECOMMUNICATION NETWORK USING MACHINE LEARNING." Journal of Ubiquitous Computing and Communication Technologies (UCCT) 1, no. 01 (2019): 33-44.

[8] Raj, Jennifer S. "A COMPREHENSIVE SURVEY ON THE COMPUTATIONAL INTELLIGENCE TECHNIQUES AND ITS APPLICATIONS." Journal of ISMAC 1, no. 03 (2019): 147-159.

[9] Bhalaji, N. "PERFORMANCE EVALUATION OF FLYING WIRELESS NETWORK WITH VANET ROUTING PROTOCOL." Journal of ISMAC 1, no. 01 (2019): 56-71.

[10] Joseph, S. Iwin Thanakumar. "SURVEY OF DATA MINING ALGORITHM'S FOR INTELLIGENT COMPUTING SYSTEM." Journal of trends in Computer Science and Smart technology (TCSST) 1, no. 01 (2019): 14-24.

ISSN: 2582-3825 (online)

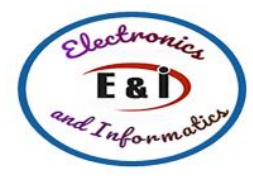


Journal of Electronics and Informatics (2019)

Vol.01/ No. 02

Pages: $89-98$

http://www.irojournals.com/iroei/

DOI: https://doi.org/10.36548/jei.2019.2.004

[11] Vijayakumar, T. "COMPARATIVE STUDY OF CAPSULE NEURAL NETWORK IN VARIOUS APPLICATIONS." Journal of Artificial Intelligence 1, no. 01 (2019): 19-27.

[12] https://medium.com/pylessons/convolutional-neural-networks-cnn-explained-step-by-step$69137 \mathrm{a} 54 \mathrm{e} 5 \mathrm{e} 7$

[13] Pandian, M. Durai. "SLEEP PATTERN ANALYSIS AND IMPROVEMENT USING ARTIFICIAL INTELLIGENCE AND MUSIC THERAPY." Journal of Artificial Intelligence 1, no. 02 (2019): 5462.

[14] https://analyticsindiamag.com/6-types-of-artificial-neural-networks-currently-being-used-in-todaystechnology/

[15] https://researchcommons.waikato.ac.nz/bitstream/handle/10289/12654/1-s2.0-S0933365717305067main.pdf?sequence $=2 \&$ is Allowed $=\mathrm{y}$

ISSN: 2582-3825 (online) 